\title{
ENSINO DE ENGENHARIA NA MODALIDADE REMOTA: A ADAPTAÇÃO DA DISCIPLINA DE SANEAMENTO BÁSICO E AMBIENTAL I
}

Paula N.de Andrade - paula.andrade@unichristus.edu.br

Centro Universitário Christus, Núcleo de Tecnologia

Avenida Dom Luis, 911, Meireles

60160-230-Fortaleza - CE

Maria Bernadette F.A. Silva-nutec01@unichristus.edu.br Centro Universitário Christus, Núcleo de Tecnologia Avenida Dom Luis, 911, Meireles

60160-230-Fortaleza - CE

Resumo: As novas diretrizes curriculares para o ensino de engenharia introduziram mudanças necessárias no sistema de ensino e aprendizagem dessa área. O isolamento social ocasionado pela pandemia da COVID-19 forçou a adaptação da educação a novas metodologias de forma abrupta e inesperada. O objetivo desse trabalho foi relatar como funcionou a experiência da transição da modalidade de ensino, que passou de presencial para ensino remoto, na disciplina de Saneamento Básico e Ambiental I do Curso de Engenharia Civil do Centro Universitário Christus (UNICHRISTUS). A disciplina foi ministrada no mesmo horário da modalidade presencial com o uso de ferramentas digitais como Google Meet e Moodle. Constatou-se que o resultado do desenvolvimento da disciplina foi satisfatório, pois foi cumprido $100 \%$ da ementa e obteve-se a aprovação de $96 \%$ dos alunos.

Palavras-chave: Ensino Remoto. Ensino por competências. Moodle.

\section{INTRODUÇÃO}

O ensino de engenharia no Brasil passou por mudanças desde a publicação das novas Diretrizes Curriculares Nacionais do Ministério da Educação, de acordo com a Resolução No 2, de 24 de Abril de 2019. O Art. $5^{\circ}$ da referida resolução, em seus incisos I, II e III, esclarece que existem três tipos de profissionais de engenharia: o engenheiro empreendedor (aquele com perfil de empresário, que tem foco no mercado, em atuar de forma autônoma ou prestando serviços para empreendimentos de maior porte), o engenheiro inovador (centrado na produção e no desenvolvimento técnico) e o engenheiro professor/pesquisador (dedicado a pesquisa acadêmica).

Com as novas diretrizes estabelecidas, o ensino de engenharia deve ser conduzido de tal forma que resulte em uma formação por competências, na qual é necessário que sejam oferecidas ao estudante ferramentas e possibilidades para que possa atuar e/ou escolher quaisquer uma dessas vertentes. Para tanto, é necessário que o aluno sinta que está em um curso de engenharia desde o início, seja pela aplicação prática das ciências básicas ou através de outras ferramentas computacionais (Art. $9^{\circ} \S 1^{\circ}$ da Resolução $n^{\circ} 2$ de 24 de abril de 2019).

Segundo Zabala (2010), existem três níveis de transformação do ensino com foco no desenvolvimento de competências: a conversão dos conteúdos tradicionais para o uso desses conteúdos sob a lógica das competências, onde o objetivo é que o aluno saiba aplicar os 
(C) COBENCE

"Os desafios para formar hoje o engenheiro do amanhã"

conhecimentos de cálculo e física em resoluções de situações ou em problemas reais (nível 1), a perspectiva da formação profissional por competências, onde os conteúdos acadêmicos convencionais não são suficientes, pois não incluem muitas das habilidades gerais das profissões (nível 2) e a formação integral dos alunos por um ensino orientado por competências, onde além de saber fazer e saber ser, o aluno deve ser ensinado a saber conviver (nível 3).

A transição da lógica do conteúdo para a lógica do uso efetivo do conhecimento é marcada pela introdução do termo competência no ensino que mobiliza habilidades e atitudes e aproxima a formação do contexto profissional. As competências transversais refletem as habilidades e atitudes que os profissionais devem demonstrar em variados contextos de trabalho, associadas às competências técnicas específicas (MORENO, 2006).

A aprendizagem por competências se converge com a aplicação de desafios, pois, assim, estimula-se a reflexão e a ação. Além do mais, esses resultados vão além de uma simples estatística entre aprovado ou não aprovado, se bem analisados podem preencher lacunas ou deficiências no aprendizado e isso vira base de alimentação do processo construtivo dos objetivos da aprendizagem. Daí a importância de entender a avaliação como etapa e não como objetivo final do processo ensino-aprendizagem (FERRAZ et al.,2019).

Nesse novo panorama, são permitidas atividades com modalidade a distância com carga horária máxima de $40 \%$ da carga horária total do curso podendo ser aplicada a disciplinas inteiras ou parte de disciplinas (Art. $2^{\circ}$ da Portaria $n^{\circ} 2.117$ de 06 de dezembro de 2019), desde que as mesmas possuam, obrigatoriamente: um tutor que seja engenheiro educador (Parágrafo único da Portaria $\mathrm{n}^{\mathrm{o}} 1.134$ de 10 de outubro de 2016), alguns encontros presenciais e todas as avaliações presenciais (Art. $1^{\circ} \S 2^{\circ}$ da Portaria $n^{\circ} 1.134$ de 10 de outubro de 2016).

Para as atividades em modalidade a distância, devem-se aplicar métodos e práticas que incorporem o uso integrado de tecnologias de informação e comunicação - atividades mediadas pela tecnologia, por exemplo, a plataforma MOODLE (Art. $2^{\circ}$ da Portaria $\mathrm{n}^{\mathrm{o}} 1.134$ de 10 de outubro de 2016), material didático específico bem como para a mediação de docentes, tutores e profissionais da educação com formação e qualificação em nível compatível com o previsto no Projeto Pedagógico do Curso (PPC) e no plano de ensino da disciplina (Art. $4^{\mathrm{o}}$ da Portaria $\mathrm{n}^{\mathrm{o}} 2.117$ de 06 de dezembro de 2019).

Além das novas diretrizes curriculares, a educação tradicional de ensino superior sofreu uma transformação significativa em decorrência da pandemia da COVID-19, doença infecciosa causada por um coronavírus recém-descoberto que possui alta transmissibilidade. Para se controlar a proliferação descontrolada do vírus, que já vitimou mais de 90 mil pessoas no Brasil (BRASIL, 2020), a Organização Mundial de Saúde (OMS) recomendou adotar-se como medida efetiva o isolamento social, que resultou no fechamento total de escolas e universidades, além de outros setores, impedindo que o ensino fosse continuado em seu formato presencial (WHO, 2020a).

Com base no que foi supracitado, este trabalho teve como objetivo relatar como funcionou a experiência da transição abrupta da modalidade de ensino, que passou de presencial para ensino remoto, na disciplina de Saneamento Básico e Ambiental I do Curso de Engenharia Civil do Centro Universitário Christus (UNICHRISTUS), instituição de ensino privada situada no município e Fortaleza, Ceará.

Além disso, foram avaliados os resultados obtidos pelos discentes da turma no semestre de 2020.1, que abrangeu o período inicial do isolamento social. 


\section{IMPLANTAÇÃO DO ENSINO REMOTO}

Com início em 29 de Janeiro de 2020, quando a situação epidêmica grave da COVID-19 concentrava-se na China e em alguns países da Europa (WHO, 2020b), as atividades acadêmicas do semestre 2020.1 ocorreram de forma presencial de acordo com a previsão do calendário acadêmico oficial da UNICHRISTUS. Na instituição, o semestre é divido em três etapas e, ao final de cada uma delas, são feitas as avaliações para compor as notas parciais.

Com o decreto $\mathrm{N}^{\mathrm{o}} 33.510$ de 16 de março de 2020 do Governo do Estado do Ceará, que decretou situação de emergência em saúde e dispôs sobre medidas para enfrentamento e contenção da infecção humana pelo novo Coronavírus, recomendou-se ao setor privado a suspensão das atividades educacionais presenciais em todas as universidades, faculdades e escolas a partir de 19 de março (Art. $3^{\circ} \S^{\circ}$ do Decreto $\mathrm{N}^{\mathrm{o}} 33.510$ de 16 de março de 2020). Portanto, após a aplicação das avaliações referentes ao primeiro período do semestre letivo, as atividades passaram a ser ministradas de forma integralmente remota.

\subsection{Metodologias e recursos utilizados}

As atividades letivas passaram a ocorrer de forma remota através da integração do Google Meet, que é o serviço de comunicação por vídeo da Google, com a plataforma Modular Object Oriented Distance Learning (Moodle), que é um modelo em software livre, utilizado como ferramenta de apoio ao ensino e à aprendizagem.

O Moodle é um ambiente virtual de aprendizagem que funciona como uma sala de aula online e concentra, num único espaço, todas as informações relativas à disciplina (Figura 1).

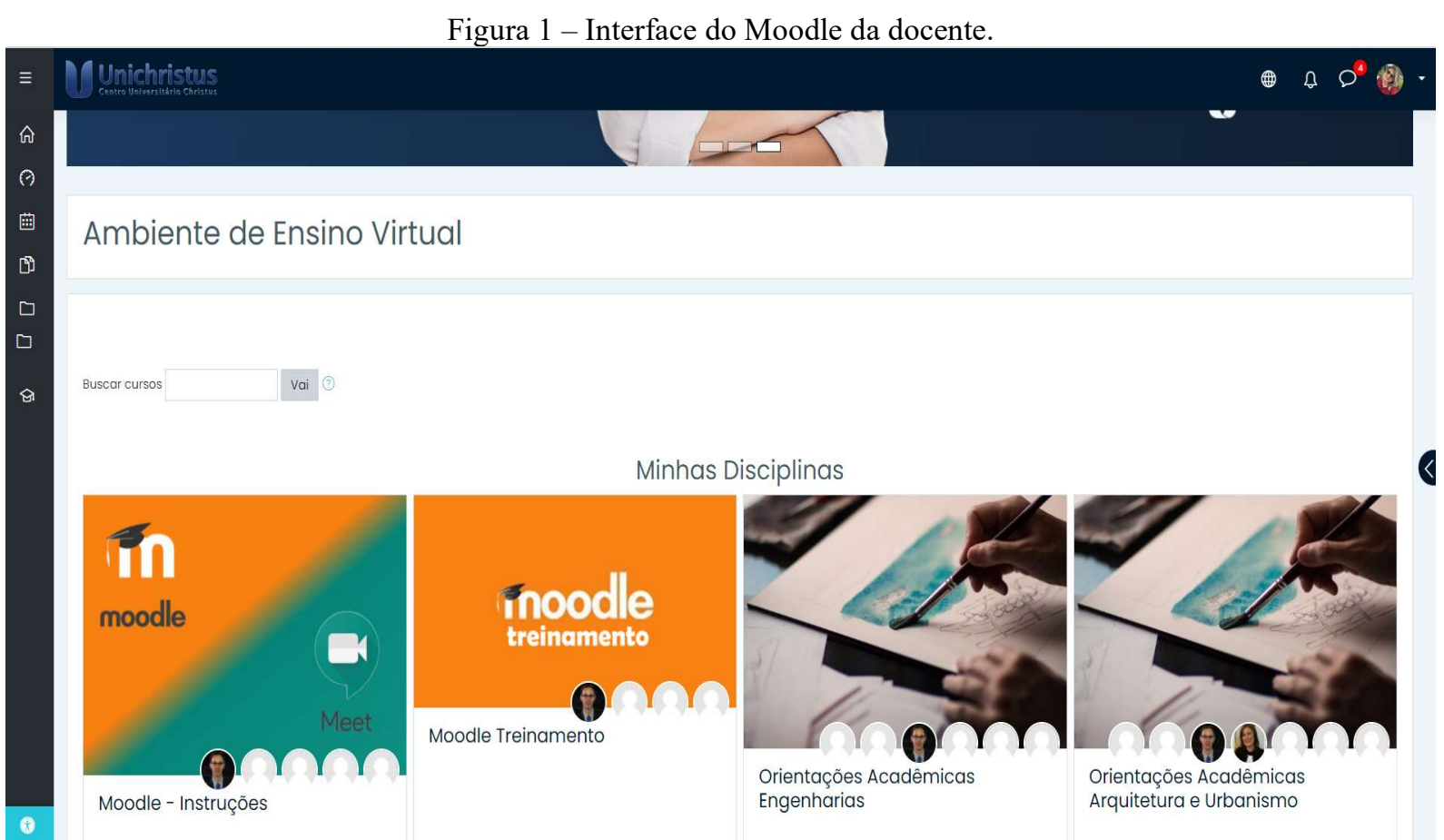

Fonte: Elaborado pelas Autoras (2020).

Dentro do ambiente virtual da disciplina, foi disponibilizado pe///la docente, a cada aula, o assunto que seria abordado com um breve resumo, juntamente com material complementar para estudo, notas de aula, chat para registro de frequência, endereço da videoconferência no Google Meet e vídeo de registro da aula (Figura 2). 
Figura 2 - Ambiente da sala de aula virtual.

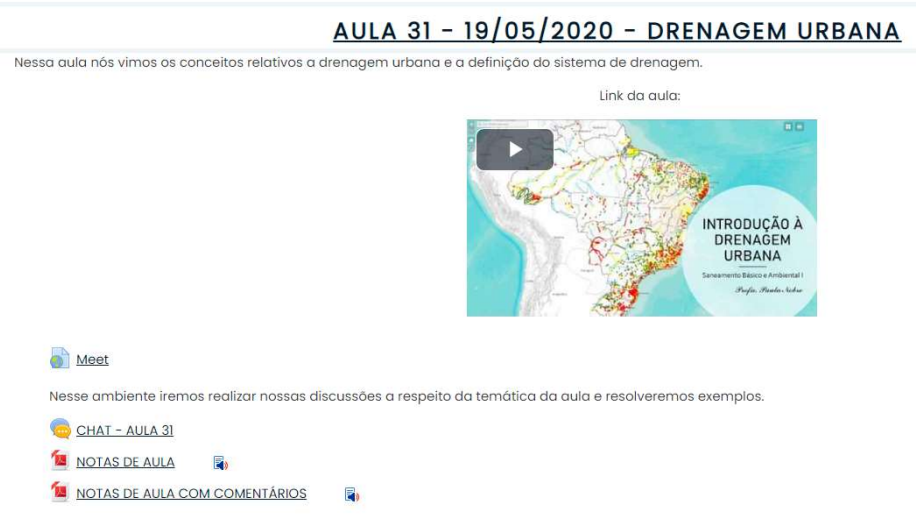

Fonte: Elaborado pelas Autoras (2020).

As aulas foram ministradas de forma remota obedecendo ao mesmo horário vigente desde o início do semestre, de acordo com a decisão institucional de não modificar a grade de horários dos alunos. Com autorização prévia dos participantes, as aulas eram gravadas e disponibilizadas pela professora em um canal na plataforma YouTube (Figura3).

O objetivo principal da criação do canal para depósito dos vídeos foi dar a possibilidade de que os discentes que não puderam, por algum motivo de força maior, comparecer à aula tivessem acesso ao conteúdo posteriormente, pois o momento da pandemia trouxe diversos reveses para o sistema ensino-aprendizagem.

Figura 3 - Canal da professora "Paula Nobre" no Youtube.

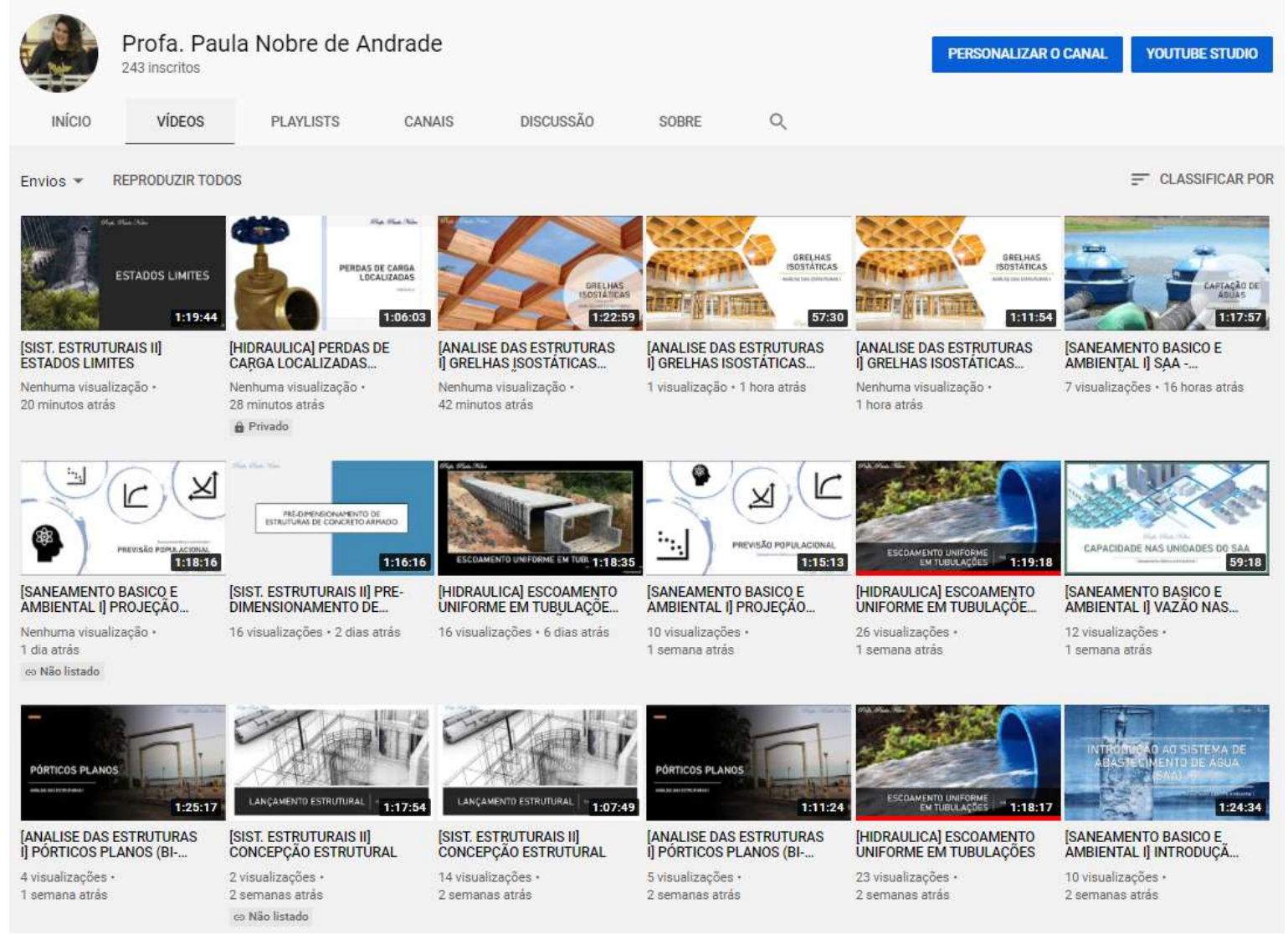

Fonte: Elaborado pelas Autoras (2020). 
Entre as adversidades enfrentadas pelos discentes no decorrer das aulas da disciplina, as mais comuns foram problemas com a conexão com a internet e a falta de um ambiente adequado e silencioso em casa para que o aluno pudesse acompanhar as aulas.

A disciplina de Saneamento Básico e Ambiental I possui diversas vertentes a serem abordadas. De ementa variada, aborda dois dos quatro pilares do saneamento básico: abastecimento humano de água e drenagem urbana. Em virtude da necessidade de se realizar cálculos e discussões, a metodologia utilizada para a disciplina foi diversificar as ferramentas disponíveis: slides, mesa digitalizadora e softwares (EPANET, Redem.exe, Canais3, ABC6 e Microsoft Excel), conforme pode ser visto na Figura 4.

O uso da mesa digitalizadora durante as aulas mostrou-se crucial, pois a ação de interatuar através da escrita manual ao invés de apenas apresentar as informações digitadas em uma apresentação aumentou a interação entre a professora e a turma, incentivando a participação dos alunos e estimulando o aprendizado.

Figura 4 - Exemplos de aplicação da mesa digitalizadora nos slides das aulas.

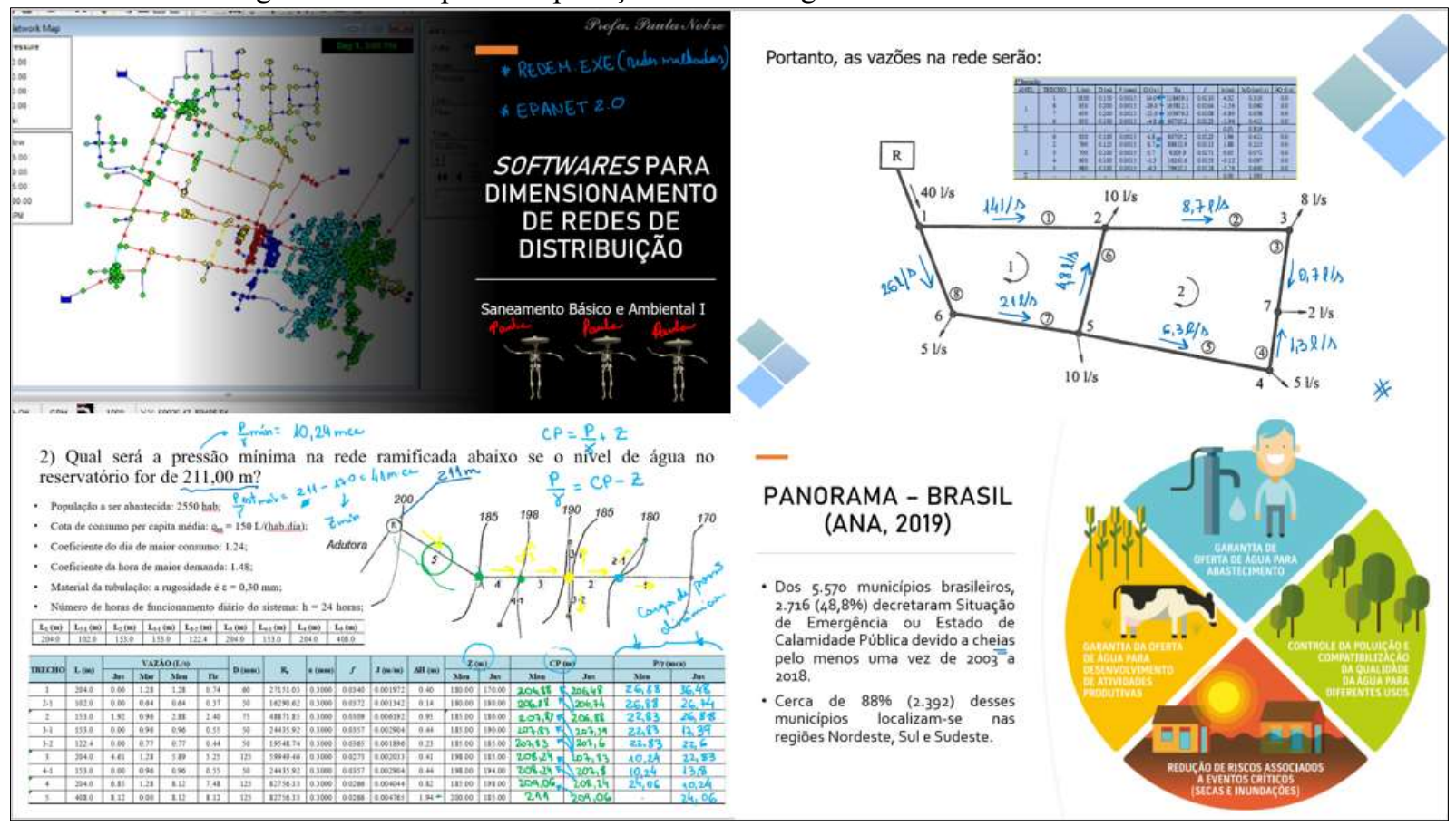

Fonte: Elaborado pelas Autoras (2020).

Além das ferramentas supracitadas, desenvolveu-se sessões intituladas como "Formação do Pensamento Crítico", onde os alunos eram instruídos a assistir vídeos de palestras de eventos internacionais relacionados aos assuntos vistos em aulas anteriores para elaborar redações elencando os conteúdos ministrados nas aulas e nas palestras.

\subsection{Avaliações remotas}

As avaliações da primeira etapa (NP1) ocorreram de forma presencial, no dia 12 de março de 2020. Logo após a aplicação da $1^{\mathrm{a}}$ avaliação parcial houve a mudança para o ensino remoto. As avaliações da segunda e da terceira etapas (NP2 e NP3) ocorreram de forma remota, através do ambiente virtual de aprendizagem da plataforma Moodle.

Por recomendações institucionais, cada questão da avaliação foi inserida em um questionário individual com tempo de disponibilidade definido de acordo com a complexidade da questão (Figura 5). 


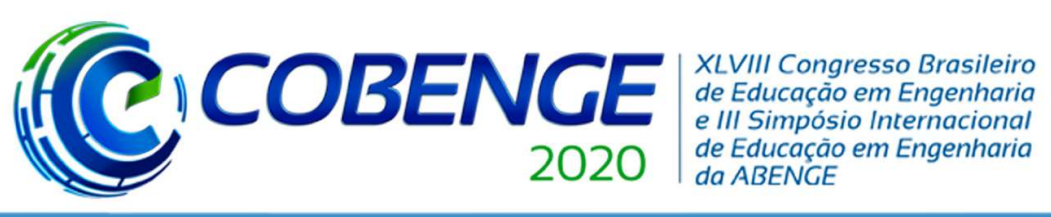

"Os desafios para formar hoje o engenheiro do amanhã"

Figura 5 - Questionários para aplicação de avaliação parcial.

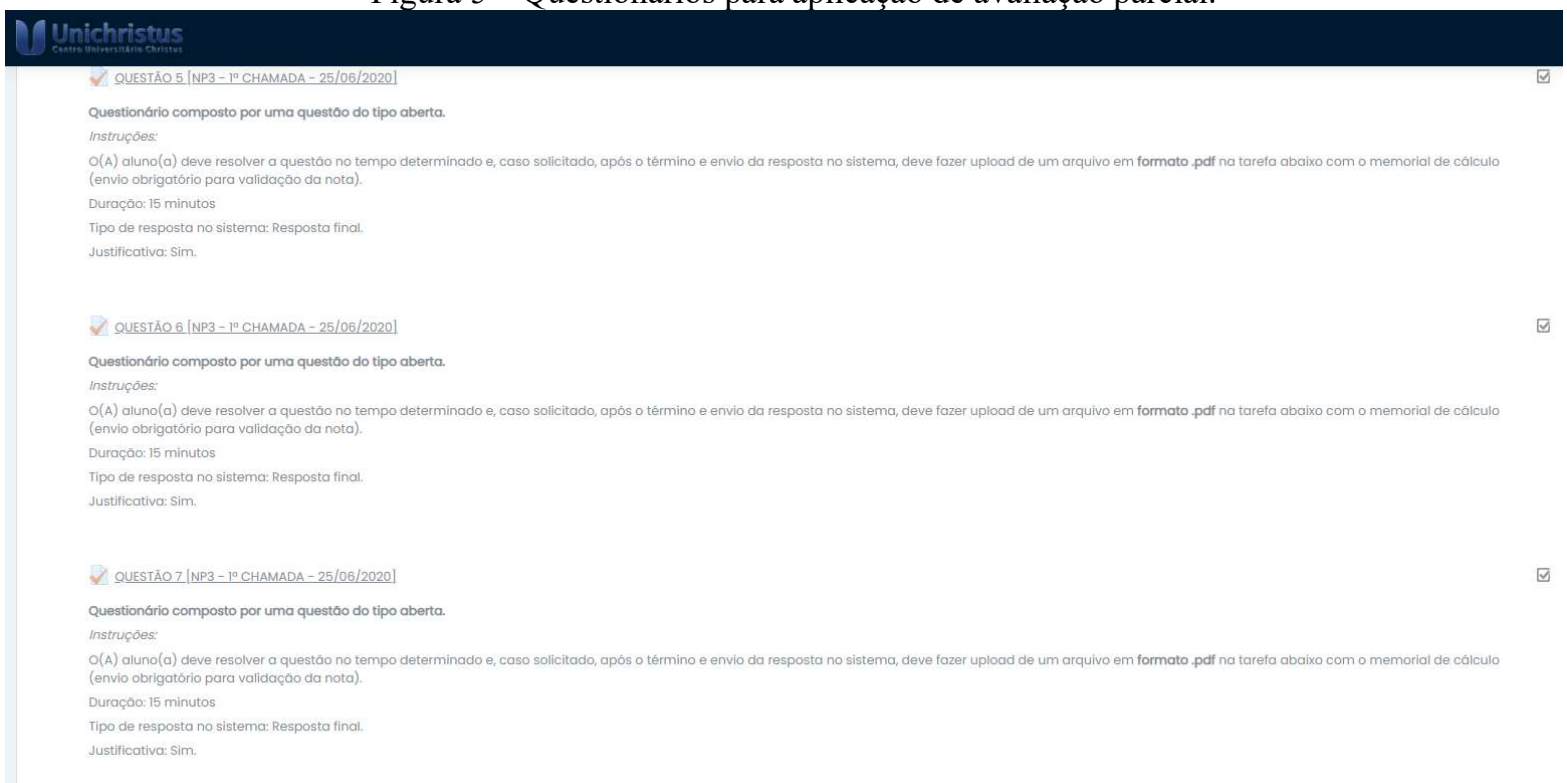

Fonte: Elaborado pelas Autoras (2020).

Os alunos tinham acesso a uma questão por vez e a resolução ia avançando de acordo com o término de cada um. As questões poderiam ou não necessitar de justificativa, que era enviada posterior ao término da prova para validação da nota.

A plataforma Moodle permite que o professor alterne a ordem de aparição das alternativas em questões de múltipla escolha e dispõe de questões de cálculo, onde é possível alternar valores para uma variável da questão. Dessa forma, as avaliações apareciam de forma individualizadas para cada aluno.

Além das avaliações parciais, também foram realizadas atividades complementares de interação como a produção de redações técnicas e aulas de exercícios em formato de gincana, onde os alunos ficavam com as câmeras ligadas e a professora lançava as perguntas em forma de desafio para estimular a participação e o estudo da matéria. Nessas atividades, constatou-se que houve mais adesão dos alunos aos exercícios propostos.

\subsection{Feedback dos alunos}

Em meio à pandemia da COVID-19, todos os envolvidos no processo de ensinoaprendizagem (instituição, corpo docente e corpo discente) foram afetados, mesmo que minimamente, seja no âmbito emocional, financeiro, acadêmico etc. Com isso, após o final do semestre, alguns alunos se corresponderam de forma voluntária com a professora para expressar suas opiniões e impressões sobre o aprendizado na disciplina.

O aluno G.A.S.S agradeceu pelo conhecimento adquirido no semestre e disse que adorou as aulas, apesar da situação difícil. Disse ainda que espera cursar outra disciplina com a docente até o final do curso.

$\mathrm{O}$ aluno L.F.C.S parabenizou a professora pelo semestre e disse que "passamos por um momento bem dificil, mas você fez um trabalho excelente e contribuiu 1000\% para nossa adaptação. A experiência com a disciplina só me fez gostar ainda mais da área".

Em consonância, a aluna A.S.G afirmou que foi a melhor disciplina do semestre e parabenizou a professora por ter se reinventado de maneira perceptível.

O aluno T.G.S. agradeceu o rendimento do semestre em nome de um grupo de alunos, pois achou que "no geral, foi tudo muito bom, apesar da pandemia, não deixou a desejar em questão de conteúdo, de didática e o seu jeito de ser deixou as aulas muito dinâmicas". 


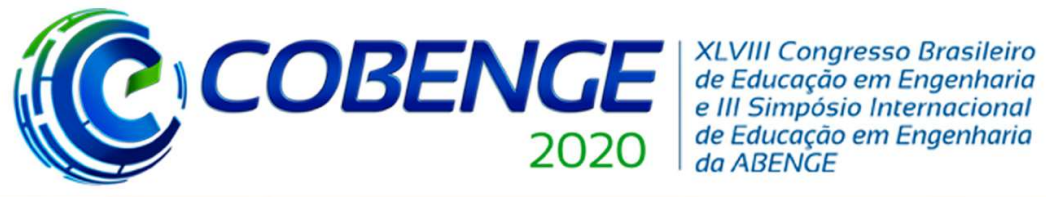

"Os desafios para formar hoje o engenheiro do amanhã"

Por fim, o aluno C.F.R.N parabenizou a professora pela organização do ambiente de ensino a distância, pois do jeito que o Moodle estava disposto era possível estudar perfeitamente, rever as aulas para sanar as dúvidas e aprender.

\subsection{Conclusão da disciplina}

O gráfico exposto na Figura 6 mostra o resultado das avaliações da disciplina de Saneamento Básico e Ambiental I nas

Figura 6 - Resultado da disciplina por etapa/aluno.

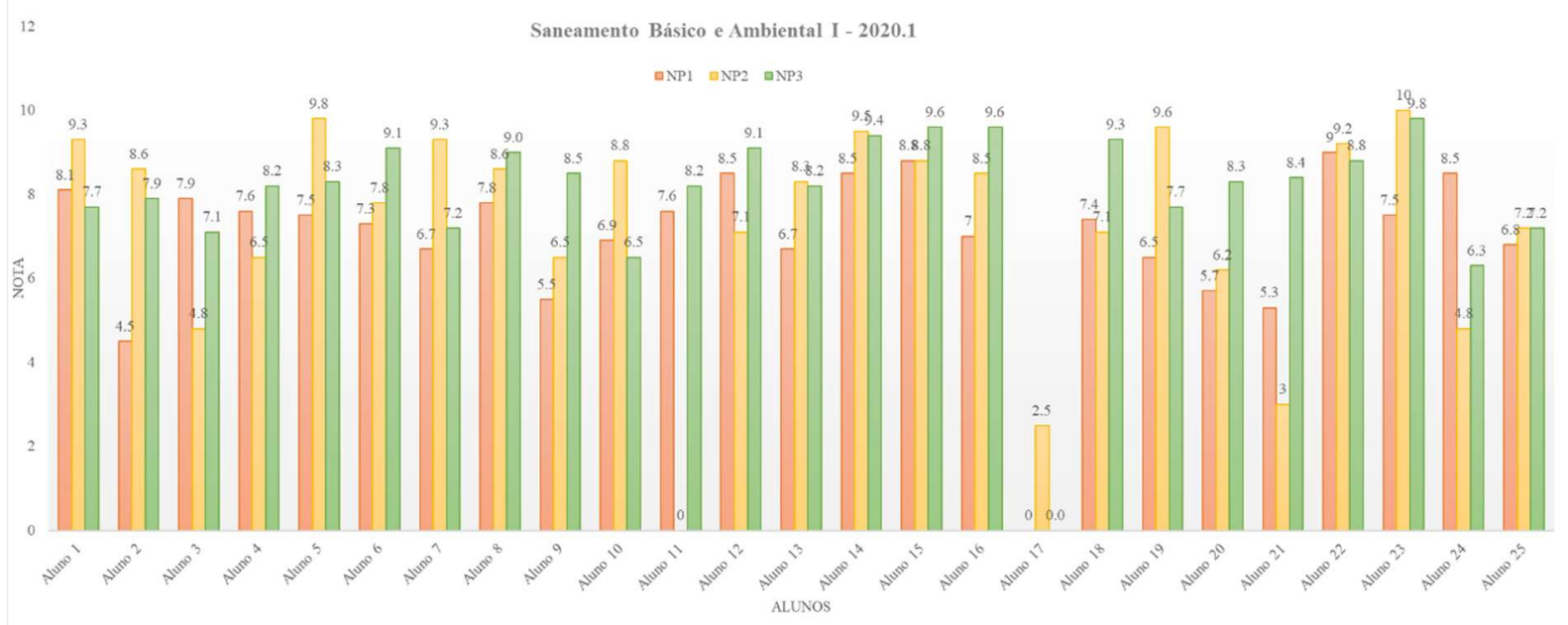

Fonte: Elaborado pela Autora (2020).

É possível notar que apenas um aluno, em 25, não concluiu a disciplina, sendo o único desistente do período. Pelos dados apresentados, é possível observar que a maioria da turma obteve desempenho de notas superior nas etapas onde o ensino foi ministrado de forma remota, pois é possível verificar que apenas dois alunos tiveram como melhor nota a NP1.

$\mathrm{Na}$ primeira etapa (NP1), a média da turma foi 6,9. Ao se analisar as notas individuais dos alunos com relação a essa média, tem-se que $36 \%$ da turma obteve nota abaixo e $64 \%$ turma obteve nota superior à média da etapa.

$\mathrm{Na}$ segunda etapa (NP2), a média da turma foi 7,3. Ao se analisar as notas individuais dos alunos com relação a essa média, tem-se que $44 \%$ da turma obteve nota abaixo e $56 \%$ turma obteve nota superior à média da etapa.

$\mathrm{Na}$ terceira etapa (NP3), a média da turma foi 8,0 . Ao se analisar as notas individuais dos alunos com relação a essa média, tem-se que 36\% da turma obteve nota abaixo e $64 \%$ turma obteve nota superior à média da etapa.

Quanto ao resultado definitivo da disciplina, após a média calculada, apenas um aluno não obteve a média exigida pela instituição para aprovação.

Portanto, é válido considerar que a disciplina de Saneamento Básico e Ambiental I do Curso de Engenharia Civil do Centro Universitário Christus foi finalizada de forma exitosa, tenho sido cumprido $100 \%$ da ementa com aprovação de $96 \%$ dos alunos.

\section{CONSIDERAÇÕES FINAIS}

Esse trabalho tratou do relato de adaptação da disciplina de Saneamento Básico e Ambiental I, ofertada para o curso de Engenharia Civil do Centro Universitário Christus durante o período de isolamento social ocasionado pela pandemia da COVID-19. 
Conforme apresentado, o ensino para o curso de Engenharia Civil já vinha sofrendo algumas exigências de modificações e adaptações ao teor mais tecnológico do curso por conta das novas diretrizes curriculares publicadas pelo Ministério da Educação. Contudo, as mudanças que seriam graduais foram executadas de forma abrupta por conta da crise na saúde pública mundial.

$\mathrm{O}$ que se observou no transcorrer do semestre é que a modalidade remota exigiu que o estudante de engenharia adquirisse um novo olhar sobre as metodologias ativas, o aprendizado por competências e o compromisso com a graduação, uma vez que o sistema de ensino e aprendizagem experienciou a inversão de valores e o professor assumiu o papel de tutor profissional, elevando a complexidade e o compromisso do aluno com sua formação.

\section{Agradecimentos}

Agradecimentos ao Centro Universitário Christus, na figura de todos que compõem a Equipe NUTEC, cujo apoio inexorável contribuiu para que o semestre pudesse ser finalizado com qualidade e motivação.

\section{REFERÊNCIAS}

BRASIL, 2020. Ministério da Saúde. Painel de casos de doença pelo coronavírus 2019 (COVID-19) no Brasil. Disponível em: < https://covid.saude.gov.br/>. Acesso em: 30 jul. 2020

CONSELHO NACIONAL DE EDUCAÇÃO. Institui as Diretrizes Curriculares Nacionais de Educação. Resolução n⿳ 2, de 24 de abril de 2019. Resolução CNE/CES 2/2019. Diário Oficial da União, Brasília, 26 de abril de 2019, Seção 1, pp. 43 e 44.

FERRAZ, T. G. A.; LORDELO, S. N. B.; SAMPAIO, R. R. Avaliação dos estudantes: o que muda e como se adequar às novas diretrizes? In: ABENGE. A engenharia e as novas DCNs: oportunidades para formar mais e melhores engenheiros. Rio de Janeiro, 2019. P. 198218.

GOVERNO DO ESTADO DO CEARÁ. Palácio da Abolição. Decreta situação de emergência em saúde e dispõe sobre medidas para enfrentamento e contenção da infecção humana pelo novo Coronavírus. Decreto $\mathbf{n}^{\mathbf{0}}$ 33.510, de 16 de março de 2020. Diário Oficial do Estado, Fortaleza, 16 de março de 2020, Série 3, Ano XII, no 053, Caderno 1/4.

MINISTÉRIO DA EDUCAÇÃO. Gabinete do Ministro. Revoga a Portaria MEC $\mathrm{n}^{\circ} 4.049$, de 10 de dezembro de 2004, e estabelece nova redação para o tema.

Portaria n⿳ 1.134, de 10 de outubro de 2016. Diário Oficial da União, Brasília, 11 de outubro de 2016, Seção 1, pp. 21.

MINISTÉRIO DA EDUCAÇÃO. Gabinete do Ministro. Dispõe sobre a oferta de carga horária na modalidade de Ensino a Distância - EaD em cursos de graduação presenciais ofertados por Instituições de Educação Superior - IES pertencentes ao Sistema Federal de Ensino. Portaria no 2.117, de 06 de dezembro de 2019. Diário Oficial da União, Brasília, 11 de dezembro de 2019, Seção 1, pp. 131. 


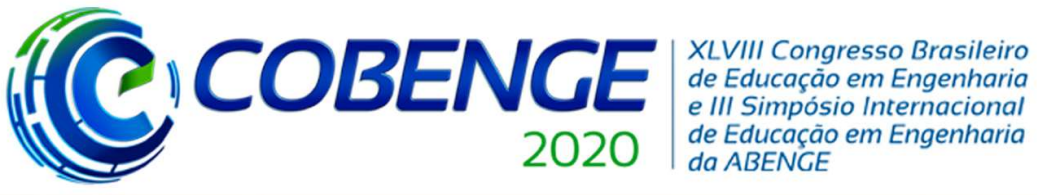

"Os desafios para formar hoje o engenheiro do amanhã"

MORENO, M. L. R. De la Evaluación a la Formación de Competencias Genéricas: Aproximación a um Modelo. Revista Brasileira de Orientação Profissional, 7(2), P. 33-38, 2006.

WHO - World Health Organization. Coronavirus Disease (COVID-19) Dashboard. 2020a. Disponível em: <https://covid19.who.int/>. Acesso em: 30 jul. 2020.

WHO - World Health Organization. Coronavirus disease 2019 (COVID-19) Situation Report - 29. 2020b. Disponível em: < https://www.who.int/docs/defaultsource/coronaviruse/situation-reports/20200218-sitrep-29-covid-19.pdf?sfvrsn=6262de9e_2>. Acesso em: 30 jul. 2020.

ZABALA, A.; ARNAU,L. Como aprender e ensinar por competências. Porto Alegre: Artmed, 2010.

\section{ENSEÑANZA DE INGENIERÍA EN MODO REMOTO: UNA ADAPTACIÓN DE LA DISCIPLINA DE SANEAMIENTO BÁSICO Y AMBIENTAL I}

Resumen: Las nuevas pautas curriculares para la enseñanza de la ingeniería introdujeron los cambios necesarios en el sistema de enseñanza y aprendizaje en esta área. El aislamiento social causado por la pandemia de COVID-19 forzó la adaptación de la educación a nuevas metodologías de manera abrupta e inesperada. El objetivo de este trabajo fue informar cómo funcionó la experiencia de la transición de la modalidad de enseñanza, que pasó de la enseñanza presencial a la remota, en la disciplina de Saneamiento Básico y Ambiental I del Curso de Ingeniería Civil del Centro Universitario Christus (UNICHRISTUS). El curso se enseñó al mismo tiempo que el modo aula utilizando herramientas digitales como Google Meet y Moodle. Se encontró que el resultado del desarrollo de la disciplina fue satisfactorio, ya que se cumplió el 100\% del menú y se aprobó el 96\% de los estudiantes.

Palabras clave: Enseñanza remota. Enseñanza basada en competencias. Moodle. 